\title{
Bibliometric Analysis of Human Factors (1970-2000): A Quantitative Description of Scientific Impact
}

\author{
John D. Lee, University of lowa, lowa City, lowa, and Andrea Cassano-Pinché and Kim \\ J. Vicente, University of Toronto, Toronto, Canada
}

\begin{abstract}
Bibliometric analyses use the citation history of scientific articles as data to measure scientific impact. This paper describes a bibliometric analysis of the 1682 papers and 2413 authors published in Human Factors from 1970 to 2000. The results show that Human Factors has substantial relative scientific influence, as measured by impact, immediacy, and half-life, exceeding the influence of comparable journals. Like other scientific disciplines, human factors research is a highly stratified activity. Most authors have published only one paper, and many papers are cited infrequently, if ever. A small number of authors account for a disproportionately large number of the papers published and citations received. However, the degree of stratification is not as extreme as in many other disciplines, possibly reflecting the diversity of the human factors discipline. A consistent trend of more authors per paper parallels a similar trend in other fields and may reflect the increasingly interdisciplinary nature of human factors research and a trend toward addressing human-technology interaction in more complex systems. Ten of the most influential papers from each of the last 3 decades illustrate trends in human factors research. Actual or potential applications of this research include considerations for the publication and distribution policy of Human Factors.
\end{abstract}

\section{INTRODUCTION}

Human factors as a discipline has rarely engaged in self-reflection (Meister, 1989; Vicente, 1997). Although it is understandable that practitioners may not have time for such lofty pursuits, the lack of attention paid by researchers to this topic is more difficult to justify. Perhaps one perceived obstacle is that abstractly reflecting on an entire discipline is a philosophical and intellectual exercise that necessarily degenerates into subjective, armchair speculation. This need not be the case.

Hull (1998) has cogently argued that it is possible to study scientific activity scientifically. Although there are many ways to do so, bibliometric analysis provides one well-proven means of achieving this goal (for an introduction, see Ikpaahindi, 1985). This type of research uses the citation history of scientific articles as data and examines how scientific contributions are accumulated and used. Bibliometric analysis has existed for decades (e.g., Dennis, 1954; Price, 1976) and has been used in many disciplines to understand better the nature of scientific activity (Cole \& Cole, 1972; Price, 1976; Simonton, 1997). For example, Valero and Monk (1998) used bibliometric analysis to position humancomputer interaction (HCI) journals relative to their parent disciplines according to an analysis of key words. However, as far as we know, no rigorous bibliometric analysis has ever been conducted in the discipline of human factors. Zavod and Hitt (2000) examined publishing trends in Human Factors from 1988 to 1997, and both Hitt (1998) and Meister (1999) conducted content analyses of papers published in the annual proceedings of the Human Factors and Ergonomics Society. Although valuable, none of these efforts used the standard quantitative measures that are typically adopted in bibliometric research (e.g., mean citation rate, impact factor). 
The work described here addresses this gap in the literature by conducting a bibliometric analysis of the 1682 papers and 2413 authors published in Human Factors from 1970 to 2000. Three issues were investigated: (a) the impact of papers published in Human Factors compared with those in other journals in the same or related disciplines; (b) whether human factors research, like that of other disciplines, is a stratified activity influenced primarily by a small number of researchers (Cole \& Cole, 1972); and (c) trends in authorship and content of highly cited papers. Although they only scratch the surface of the potential that bibliometric analyses have for the human factors discipline, these analyses represent a novel and significant contribution to the understanding of what it means to engage in human factors research.

Like any other measure, bibliometric data have limitations. Depending on the purpose of the evaluation, citation history may not be the only or even the best measure of impact (Schoonbaert \& Roelants, 1996; Snyder, Cronin, \& Davenport, 1995). Other potential measures include the frequency with which a paper is read, the number of subsequent papers it inspires, the frequency with which it is used to guide design or public policy decisions, and the quality of the design decisions that were supported by it. Obviously these measures are virtually impossible to obtain for any one paper, let alone for hundreds of them. Although imperfect, the citation history of a paper reflects its impact on scholarship and the advancement of research (Garfield \& Welljams-Dorof, 1992). The citation rate of each paper published in a journal can be used as an approximate, retrospective "gold standard" measure of its actual impact (Narin \& Hamilton, 1996; Zuckerman, 1977).

\section{METHOD}

The ISI Web of Science electronic database (www.isiknowledge.com) was used to compile the citation history of papers published in $\mathrm{Hu}$ man Factors. The ISI Journal Citation Reports were used to collect data on the citation history of the journal as a whole. The Web of Science provides an on-line database that catalogs journal papers and their citation history, including papers published in Human Factors. This data- base includes papers from approximately 5225 journals; it lists the papers cited by each paper and identifies papers in the 5225 journals that cite each paper. ISI also provides a database, Journal Citation Reports, which catalogs the overall citation history of each journal. Electronic data were available from 1970 onward, so data were collected for papers published in Human Factors between 1970 and 2000. The Web of Science allows one to select all the articles for a given year for a particular publication. Using this feature, we selected the papers for each year of Human Factors, and the data describing each paper were entered into a database for analysis. A total of 1682 Human Factors papers - every paper published between 1970 and 2000 - were included in the resulting citation database. This database recorded the title of each paper, the authors, the date of publication, the number of citations received each year, and the total number of citations received (as of May 2001). Each entry in the database was verified to ensure consistent spelling of authors' names. Although the data can be downloaded electronically, the process of data compilation, transformation, and verification took many hours.

This sample has several important limits that may constrain the generality of our findings. First, the database is limited to a single journal and so does not contain all of the publications of some authors. Second, it is restricted to 30 years of publications in one journal and so almost certainly does not capture the lifetime contributions of some authors.

From this basic database, two additional databases were developed to support the citation analysis. One database characterized the authors of the papers. The author database described the publication and citation history of the 2413 authors who contributed to Human Factors between 1970 and 2000, inclusively. The data included the number of papers written by each author, the citation rate of each author (total citations to the papers the author has published in Human Factors divided by the number of years since each paper was published), and the total number of citations received by each author. These data count every instance in which a given person appeared as an author in the 30 years of Human Factors papers and every instance in 
which one of their papers was cited by any of the journals in the ISI database. The second database characterized the citation history of each paper. This database included the title, date of publication, number of citations in each year since publication, citation rate of each paper (total citations to the paper divided by the number of years since the paper was published), and publication history of each contributing author as described in the author database (papers written, citation rate, total citations).

\section{RESULTS AND DISCUSSION}

\section{Journal Impact and Citation Dynamics}

Table 1 compares citations of Human Factors with those of related journals on the basis of immediacy, impact, and half-life. These data come from the ISI Journal Citation Reports and are computed for the journal as a whole. For each of these measures, the number of citations refers to the total number of times papers in Human Factors were cited by any of the approximately 5225 journals tracked by the ISI database.

Immediacy is defined by the number of citations to papers published by a journal in a given year divided by the number of papers published in that year. Impact is defined by the total citations to papers published in the last 2 years divided by the total number of papers published during that period. Impact measures the frequency of citation for an average paper and reflects the long-term influence of such a paper, whereas immediacy reflects how quickly an average paper is cited. As immediacy and impact depend on both the number of citations and the number of papers, a journal that produces relatively few papers might have an inflated impact factor. This is particularly important to remember when comparing a journal such as Ergonomics, which publishes approximately 70 papers each year, with one such as Human Factors, which has published an average of just over 54 papers per year. The impact factor of Ergonomics is lower than that of Human Factors even though it might receive more total citations. The half-life is the number of years of publication, going back from the current year, that account for $50 \%$ of the total citations received by the journal. The citation half-life indicates the age of the papers that tend to be cited from the jour- nal; journals in highly dynamic fields tend to have a short half-life, and journals with influential older papers have a long half-life.

Table 1 shows the immediacy, impact, and half-life of 10 journals for the year 2000 as well as the means and standard deviations for the previous 5 years. Because many of the journals are relatively new, it is not possible to calculate these values for all of them. Table 1 shows that Human Factors has the highest impact factors and the longest half-life of the journals considered. The product of the half life and the impact factor has been used to rank journals to determine which journals to keep on subscription lists (Garfield, 1994). On this measure, Human Factors ranks substantially higher than others. Overall, the data for the year 2000 are relatively representative of the previous 5 years.

The impact factor of all of the journals listed in Table 1 is low compared with the most influential journals in psychology (e.g., Psychological Review and Psychological Bulletin have impact factors of 6.87 and 6.91, respectively) or general science (e.g., Science and Nature have impact factors of 23.87 and 28.69, respectively). Interestingly, the impact of a journal is not dependent on the size of the research community it serves, because a larger community means a greater number of papers to share the citations; however, the size of the community does influence the number of extremely highly cited papers and highly cited journals (Garfield, 1999). Circulation does have a modest association with the impact factor, with a rank correlation ranging between .25 and .50 for journals from 21 disciplines (Peritz, 1995). Other factors that influence the impact of journals include the citation conventions between fields, such as the typical number of citations per paper, and the degree to which the journal publishes basic or applied research. Basic research journals act as a source of knowledge and tend to have a high number of citations, whereas applied journals tend to integrate the results from the basic research and disseminate it to practitioners (Luukkonen, 1990). Basic research journals tend to be cited by other journals, whereas more applied journals are likely to cite other journals. As an example, the ratio of papers cited by Human Factors papers to papers citing Human Factors papers is 0.749 , compared with 1.69 for Psychological Bulletin 
TABLE 1: Immediacy, Impact, and Half-Life of a Sample of Journals in the Human Factors and Ergonomics Domain

\begin{tabular}{|c|c|c|c|c|}
\hline & Immediacy & Impact & Half-Life & Half-Life $\times$ Impact \\
\hline $\begin{array}{l}2000 \\
1996-2000 \text { mean } \\
(S D)\end{array}$ & $\begin{array}{c}0.076 \\
0.137 \\
(0.073)\end{array}$ & $\begin{array}{c}\text { Ergonon } \\
0.642 \\
0.498 \\
(0.131)\end{array}$ & $\begin{array}{l}7.9 \\
8.22 \\
(0.47)\end{array}$ & 5.07 \\
\hline $\begin{array}{l}2000 \\
1996-2000 \text { mean } \\
(S D)\end{array}$ & $\begin{array}{c}\text { Aviation, } \mathrm{Sp} \\
0.103 \\
0.118 \\
(0.050)\end{array}$ & $\begin{array}{c}\text { Environr } \\
0.658 \\
0.564 \\
(0.061)\end{array}$ & $\begin{array}{c}\text { edicine } \\
9.2 \\
8.88 \\
(0.22)\end{array}$ & 6.05 \\
\hline $\begin{array}{l}2000 \\
1996-2000 \text { mean } \\
(S D)\end{array}$ & $\begin{array}{l}\text { Behaviou } \\
0.225 \\
0.083 \\
(0.185)\end{array}$ & $\begin{array}{c}\text { formatior } \\
0.413 \\
0.276 \\
(0.110)\end{array}$ & $\begin{array}{l}\text { ogy } \\
7.2 \\
6.76 \\
(0.76)\end{array}$ & 2.97 \\
\hline $\begin{array}{l}2000 \\
1996-2000 \text { mean } \\
(S D)\end{array}$ & $\begin{array}{c}0.123 \\
0.094 \\
(0.021)\end{array}$ & $\begin{array}{c}\text { onomics } \\
0.691 \\
0.625 \\
(0.111)\end{array}$ & $\begin{array}{l}9.9 \\
9.77 \\
(0.12)\end{array}$ & 6.84 \\
\hline $\begin{array}{l}2000 \\
1996-2000 \text { mean } \\
(S D)\end{array}$ & $\begin{array}{c}0.083 \\
0.101 \\
(0.083)\end{array}$ & $\begin{array}{c}0.954 \\
0.762 \\
(0.137)\end{array}$ & $\begin{array}{l}9.5 \\
9.73 \\
(0.25)\end{array}$ & 9.06 \\
\hline $\begin{array}{l}2000 \\
1996-2000 \text { mean } \\
(S D)\end{array}$ & $\begin{array}{c}\text { Human Factor } \\
0.042 \\
0.008 \\
(0.019)\end{array}$ & $\begin{array}{c}\text { gonomics } \\
0.136 \\
0.183 \\
(0.124)\end{array}$ & $\begin{array}{c}\text { facturing } \\
\text { n.a. }\end{array}$ & n.a. \\
\hline $\begin{array}{l}2000 \\
1996-2000 \text { mean } \\
(S D)\end{array}$ & $\begin{array}{c}\text { IEEE Transaction } \\
0.025 \\
0.034 \\
(0.031)\end{array}$ & $\begin{array}{c}\text { ems, Ma } \\
0.557 \\
0.458 \\
(0.138)\end{array}$ & $\begin{array}{c}\text { bernetics } \\
3.3 \\
3.20 \\
(0.14)\end{array}$ & 1.84 \\
\hline $\begin{array}{l}2000 \\
1996-2000 \text { mean } \\
(S D)\end{array}$ & $\begin{array}{c}\text { International Jo } \\
0.000 \\
0.000 \\
(0.000)\end{array}$ & $\begin{array}{c}\text { Human-C } \\
0.529 \\
0.530 \\
(0.140)\end{array}$ & $\begin{array}{l}\text { Interaction } \\
\text { n.a. }\end{array}$ & n.a. \\
\hline $\begin{array}{l}2000 \\
1996-2000 \text { mean } \\
(S D)\end{array}$ & $\begin{array}{c}\text { International J } \\
0.083 \\
0.023 \\
(0.034)\end{array}$ & $\begin{array}{l}\text { Human- } \\
0.333 \\
0.300 \\
(0.061)\end{array}$ & $\begin{array}{c}\text { Studies } \\
4.4 \\
3.63 \\
(0.68)\end{array}$ & 1.46 \\
\hline $\begin{array}{l}2000 \\
1996-2000 \text { mean } \\
(S D)\end{array}$ & $\begin{array}{c}\text { Internationa } \\
0.055 \\
0.064 \\
(0.006)\end{array}$ & $\begin{array}{c}\text { of Indus } \\
0.255 \\
0.300 \\
(0.061)\end{array}$ & $\begin{array}{l}\text { nomics } \\
6.2 \\
5.50 \\
(0.74)\end{array}$ & 1.58 \\
\hline
\end{tabular}

Note. These journals are the ones that most frequently cite papers in Human Factors and are included in the ISI database; n.a. = data are not available (e.g., the half-life is calculated only for those journals receiving more than 100 citations).

and 0.286 for Applied Ergonomics. In part, this ratio reflects the degree to which each journal generates or accumulates knowledge. For this reason, comparisons are most meaningful between journals within a discipline.

Impact, immediacy, and half-life are summary measures that reflect general features of the citation dynamics of papers. Figure 1 presents a more detailed picture of citation dynamics, with the mean citation rate in the years following the publication of a paper. This figure shows a peak citation rate 4 years after publication and a continued influence that gradually declines. A small proportion of Human Factors papers are cited 


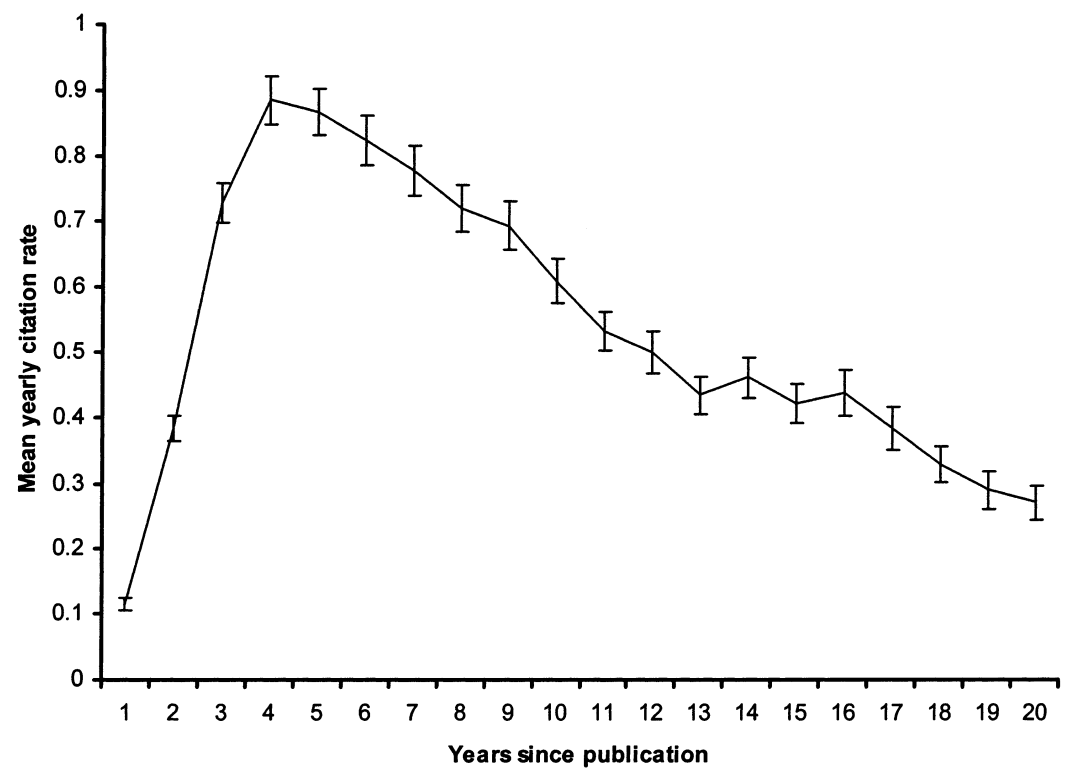

Figure 1. Mean number of citations in each of the 20 years following publication of Human Factors papers published from 1970 to 2000.

within the 1 st year $-90.7 \%$ of papers are not cited in the year following publication, and the mean citation rate in the 1st year (immediacy) is only 0.115 . However, only $25.5 \%$ of papers have not been cited 5 years after publication, and the mean citation rate per year is 0.592 for the 5 years after publication. The pattern of citation rates in Human Factors compares quite favorably with the citation rates for other disciplines as a whole (i.e., across journals). The percentage of papers that have not been cited after 5 years of publication is lowest in the basic sciences - for example, in disciplines such as atomic, molecular, and chemical physics $(9.2 \%)$ - and highest in general engineering (86.9\%; Hamilton, 1991).

One important trend that is likely to affect the impact of Human Factors and other journals in the field is the movement toward greater availability of electronic versions of papers on the Internet. Analysis of a sample of papers from computer science proceedings showed that papers that are freely available on line tend to be cited more frequently (Lawrence, 2001). These computer science papers included papers from highly prestigious conferences with acceptance rates of less than $10 \%$, and so they represent rigorously reviewed papers that are available electronically in addition to being available in print. Papers available on line receive 336\% more citations than those that are not; however, the cause of this effect is not clear (Lawrence, 2001). One reason for the greater impact is that on-line papers are likely to be more easily available, and so the barriers to citation are lower. Alternatively, papers that are available on line may be of generally higher quality because the most prestigious print journals (e.g., Science and Nature) generally have some or all of their content available on line. In either case, the electronic distribution of papers is strongly related to impact, and this relationship is likely to strengthen in the future. Although Lawrence (2001) focused on computer science, others have considered the effect of Web-based content on impact in other domains. For instance, the number of links from other Web sites to a journal's Web site is correlated with the journal's impact factor, and the information content of the Web site (e.g., title vs. title and abstract vs. full text) is correlated with the number of links to the Web site (Vaughan \& Thelwall, 2003). Journals with high-content Web sites tend to have greater impact.

\section{Stratification of Productivity and Impact}

Scientific contributions in many disciplines show a high degree of stratification for both 
individual researchers and papers (Cole \& Cole, 1972; Zuckerman, 1977). Most of the papers are written by a small number of authors, and most of the citations are garnered by a small number of papers.

The stratification of authors has been labeled the Matthew effect (Merton, 1968), which states that a few researchers account for most of the papers and citations. This phenomenon has been observed in many disciplines. In a sample from psychology, the most productive $10 \%$ of authors produced $47 \%$ of publications, whereas the least productive $50 \%$ of authors accounted for only $7 \%$ of publications (Dennis, 1954). Similarly, in a sample from physics, the most productive $10 \%$ of authors produced $50 \%$ of papers, whereas the least productive $50 \%$ of authors accounted for only $15 \%$ of papers (Cole \& Cole, 1972).

The Matthew effect is so robust that it has been captured quantitatively in several forms. Price's law states that the square root of the number of contributors in the field equals the number of individuals who account for $50 \%$ of contributions (Price, 1976). Lotka's law states that the number of individuals who produce $n$ papers is inversely proportional to $n^{2}$ (Lotka, 1926, as cited in Simonton, 1997).

The Matthew effect can also be observed in the publication rate for contributors to Human Factors. From 1970 to 2000, there were 1170 authors who contributed as the first author to at least one of 1682 papers, whereas 1234 authors did not contribute a single paper as the first author. First-author publications (i.e., publications in which the author in question was the first author) are typically used in bibliometric analysis, a practice we follow here. Ten percent of the most productive first authors wrote 674 papers ( $40.1 \%$ of the total), $914(78.1 \%)$ authors were the first author on only 1 paper, and the least productive $50 \%$ of first authors contributed $34.8 \%$ of the papers. Each of the least productive authors contributed only 1 paper.

According to Price's (1976) law, the 34 $\left(1170^{0.5}\right)$ most productive authors should account for $50 \%$ of the papers. The results show that they account for 285 papers, or $16.9 \%$ of the papers, which is substantially less than the predicted $50 \%$. However, only 256 authors $(21.9 \%)$ contributed more than one paper as a first author, and only $106(9.1 \%)$ contributed more than two. Although only 31 authors contributed more than four papers as the first author, they account for $13.2 \%$ of all papers and $15.8 \%$ of the total citations of the journal. In combination, these results show that like other fields, the human factors discipline is dominated by a relatively few highly productive individuals (see Figure 2). However, the field is not as highly stratified as others and is less stratified than some empirical laws, such as Price's (1976) law, would predict.

One explanation for this finding is that this analysis focuses on a journal, not a discipline. Human Factors is a publication venue for a relatively heterogeneous group of researchers and practitioners who publish work that spans wide disciplinary boundaries - the difference between cognitive engineering and physical ergonomics being a simple example. Such heterogeneity might diminish the tendency of self-citation, colleagueship, and student-teacher relationships that concentrate productivity. Many highly productive authors might publish in Human Factors only occasionally, diminishing the skew predicted by Lotka's law. Although highly stratified, the diversity of topics included in Human Factors may promote a relatively broad distribution of author productivity.

There is a similar tendency for a few papers to produce a disproportionate scientific impact. Of the papers published in the journals included in the ISI citation database, $55 \%$ were not cited within 5 years of publication, leading to a modal citation rate of zero (Hamilton, 1991). In our sample, $25.5 \%$ of the papers were not cited within 5 years of publication, and the modal number of citations in the first 5 years was also zero (see Figure 3). Based on the number of citations in the first 5 years after publication, 10\% of the most frequently cited papers (147 papers) account for $37.9 \%$ of the total citations to the journal. A similar pattern occurs when the entire citation history of papers is considered. Of all the Human Factors papers published between 1970 and 2000, only 2 have been cited more than 100 times, and 294 and have never been cited. Lee, Vicente, Cassano, and Shearer (2003) analyzed papers receiving the annual award for the best paper published in Human Factors and found that award-winning papers were cited somewhat more frequently (1.32 vs. 0.59 times 


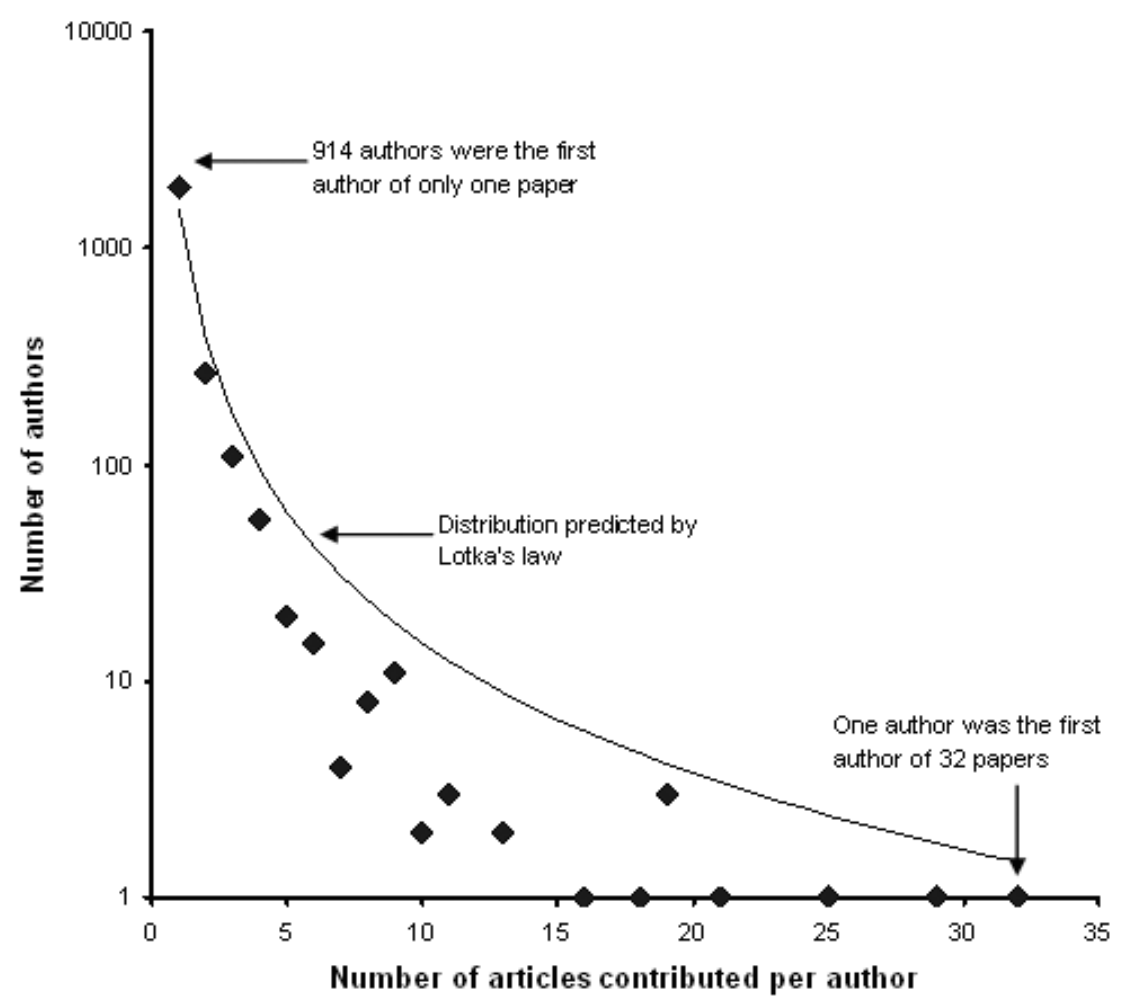

Figure 2. The distribution of author productivity, as measured by the number of papers published as a first author. Many authors write only one paper, and few write many papers.

per year), $F(1,1680)=24.15, p<.001$, compared with those that did not receive the award; however, only 1 of the award-winning papers was among the 20 most-cited papers of the last 30 years. Prospective identification of the most highly influential papers appears to be quite difficult (Simonton, 1997). As Figure 3 shows, similar to the distribution of papers contributed per author, relatively few papers account for most of the citations.

Not surprisingly, highly productive authors also tend to receive a large number of citations in total. Figure 4 shows the distributions of total citations per author; like paper production and the number of citations per paper, the distribution is highly skewed, with a few authors accounting for many citations. The most frequently cited author has been cited 568 times, the 5 next most-cited authors were cited approximately 235 times each, and 353 authors have never been cited. The most-cited author accounts for more citations than do $30.9 \%$ of the least-cited authors combined.
Previous bibliometric analysis has demonstrated that highly productive authors also tend to be highly influential, as measured by the combined citation rate of all of their contributions (Dennis, 1954; Rushton, 1984). This relationship holds true even when impact is measured only by the author's most highly cited paper, ignoring all other contributions. The same holds true with authors of papers in Human Factors. The number of papers produced by a particular author is a very strong predictor of the total citations of that author, with a linear regression predicting $58.1 \%$ of the variance in the author's total citations, $F(1,2411)=3338.7, p<.0001$. Similarly, the total number of papers produced by authors is indicative of the number of citations they receive for their most-cited paper, $F(1,2411)=269.3, p<.0001$.

To assess whether the average paper of the most productive authors is more highly cited, we compared the citation rate per paper of the most and least productive authors. Authors who contributed more than three papers as a first 


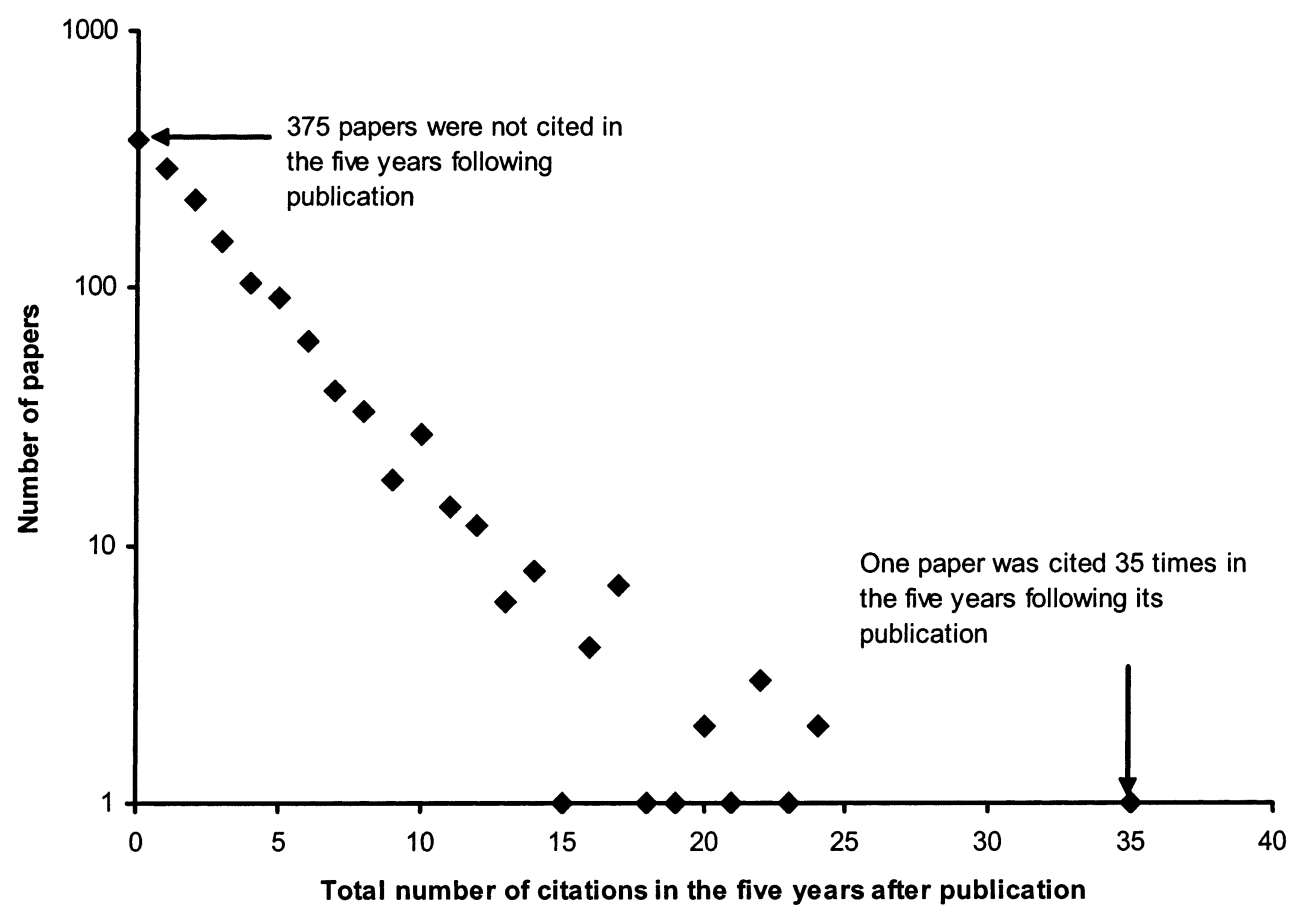

Figure 3. The distribution of the citations per paper in the 5 years following publication. Many papers are cited very infrequently, and a few are cited frequently.

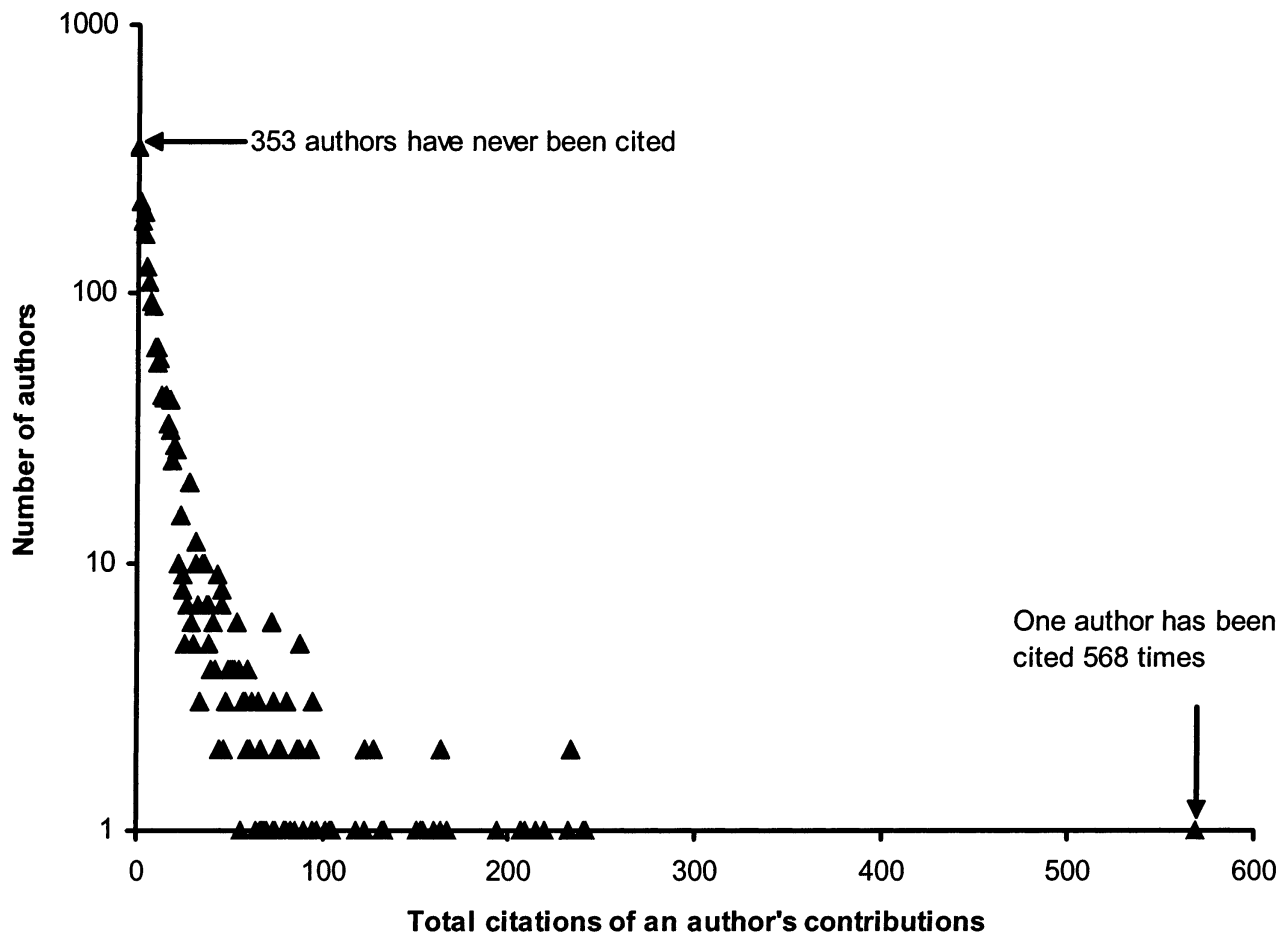

Figure 4. The distribution of total citations received by authors for their papers published in Human Factors. Some authors are never cited, and others are cited very frequently. 
author had a mean citation rate of 0.732 citations per paper, compared with 0.535 for those who contributed fewer than three papers, $F(1,1168)=$ $7.69, p=.006$. Similarly, those who wrote more than five papers had a citation rate of 0.872 per paper, compared with 0.544 for those who wrote fewer than five papers, $F(1,1168)=6.66, p=$ 0.010 . More generally, the number of first-author publications (i.e., the number of papers in which the author in question was the first author) was a weak predictor of the citation rate per paper, accounting for only $0.8 \%$ of the variance in citation rates, $F(1,1168)=8.87, p=.003$. Considering all contributions by all authors, the number of publications is also a weak predictor of the citation rate per paper, accounting for only $0.2 \%$ of the variance in citation rates, $F(1,2411)=5.58$, $p=.018$. These results suggest that there is a weak link between productivity and the impact of any one paper; however, highly productive authors are very likely to be highly cited, a result consistent with Simonton's (1997) model of creative productivity.

To summarize, a few authors write most of the papers, a few papers receive most of the citations, highly productive authors are likely to receive many citations, and any given paper of a highly productive author is only slightly more likely to be highly cited as compared with that of an average author. Highly productive authors receive a large number of citations because they write many papers.

The competing processes of diversification and cumulative advantage help explain the concentration of author productivity and citations per paper (White \& McCain, 1989). Cumulative advantage describes a positive feedback process in which one occurrence makes others more likely. Diversification describes an opposing process in which one occurrence makes others less likely. Cumulative advantage concentrates author productivity because each successful journal publication makes the next effort more likely to succeed. Cumulative advantage also concentrates the citation rate of papers because each citation of a paper makes the paper more visible and likely to be cited. Diversification moderates the concentrating effect of cumulative advantage. Diversification leads authors to distribute papers across journals, and it leads editors to distribute available journal pages across authors and topics. Very few extremely productive authors would publish in only one journal, and journals tend to publish papers on a variety of topics from many authors. Diversification also leads researchers to go beyond the "classic" papers and cite papers with innovative perspectives, which increases the breadth of a literature review. Diversification and cumulative advantage provide a theoretical basis that predicts the highly skewed, scale-dependent, power law distributions described by Mandelbrott and Zipf (as cited in White \& McCain, 1989), which apply to a wide variety of phenomena ranging from word frequency to citation frequency. In Human Factors, the relatively modest stratification of author productivity and citation rates reflects the strong influence of diversification relative to cumulative advantage.

\section{Trends in Content and Authorship}

Table 2 shows the papers with the greatest impact, as measured by the number of citations garnered within 5 years of publication. These highly cited papers provide a snapshot of the trends in content and authorship over the last 3 decades of Human Factors publication. The topic of mental workload and dual-task performance was a persistent topic through the 1970s and 1980s, with three highly cited papers in each decade on these topics. Only one highly cited paper addressed mental workload in the 1990s, and it was published in 1991. Display design is another important topic, with three papers addressing it in the 1980s and two in the 1990s. Interestingly, no highly cited papers addressed display design in the 1970s. Situation awareness emerged as an important topic in the 1990s, as evidenced by three highly cited papers on that topic. More generally, an overwhelming proportion of the most highly cited papers have addressed cognitive issues rather than physical issues: No highly cited papers in the 1970s focused on physical limits, and there was only one each in the 1980s and 1990s. Another general feature of highly cited papers is that they are domain independent; only a few focus on a specific application domain. The exception is a consistent focus on driving-related papers. Each decade included a highly cited driving-focused paper, and the 1990s had two. 


\section{Published 1970-1979}

Effects of Psychotropic Drugs Upon Driving-Related Skills (Clayton, 1976)

Measurement of Workload by Secondary Tasks (Ogden, Levine, \& Eisner, 1979)

Nonparametric Measures of Sensory Efficiency for Sustained Monitoring Tasks

(Craig, 1979)

Control-Theory Measures of Tracking as Indexes of Attention Allocation

Strategies (Wickens \& Gopher, 1977)

Inspection of Sheet Materials: Model and Data (Drury, 1975)

Problem-Solving Performance of Maintenance Trainees in a Fault Diagnosis Task (Rouse, 1979)

Effects of Alcohol on Peripheral Vision as a Function of Attention (Moskowitz \& Sharma, 1974)

Studies in Interactive Communication 1: Effects of Four Communication Modes on Behavior of Teams During Cooperative Problem-Solving (Chapanis, Ochsman, Parrish, \& Weeks, 1972)

Physiological Measures of Aircrew Mental Workload (Wierwille, 1979)

Shiftwork and Performance (Folkard \& Monk, 1979)

\section{Published 1980-1989}

The Spatial Allocation of Visual Attention as Indexed by Event-Related Brain Potentials (Mangun \& Hillyard, 1987)

An Investigation of Health Complaints and Job Stress in Video Display Operations (Smith, Cohen, Stammerjohn, \& Happ, 1981)

Training High-Performance Skills: Fallacies and Guidelines (Schneider, 1985)

The Role of Practice in Dual-Task Performance: Toward Workload Modeling in a Connectionist Control Architecture (Schneider \& Detweiler, 1988)

Doing the Same Work With Hard Copy and With Cathode-Ray Tube (CRT) Computer Terminals (Gould \& Grischkowsky, 1984)

Multiple Resources, Task-Hemispheric Integrity, and Individual Differences in Time-Sharing (Wickens, Mountford, \& Schreiner, 1981)

Object Displays Do Not Always Support Better Integrated Task Performance (Sanderson, Flach, Buttigieg, \& Casey, 1989)

Compatibility and Resource Competition Between Modalities of Input, Central Processing, and Output (Wickens, Sandry, \& Vidulich, 1983)

Human-Behavior Feedback and Traffic Safety (Evans, 1985)

An Isoinertial Technique to Assess Individual Lifting Capability (Kroemer, 1983)

\section{Published 1990-1995}

Toward a Theory of Situation Awareness in Dynamic Systems (Endsley, 1995b)

The Proximity Compatibility Principle: Its Psychological Foundation and Relevance to Display Design (Wickens \& Carswell, 1995)

Graphical Displays: Implications for Divided Attention, Focused Attention, and Problem Solving (Bennett \& Flach, 1992)

Identifying Correlates of Accident Involvement for the Older Driver (Ball \& Owsley, 1991)

A Three-Dimensional Motion Model of Loads on the Lumbar Spine: 1. Model Structure (Marras \& Sommerich, 1991)

Measurement of Situation Awareness in Dynamic Systems (Endsley, 1995a)

How in the World Did We Ever Get into that Mode? Mode Error and Awareness in Supervisory Control (Sarter \& Woods, 1995)

Psychometric Properties of Subjective Workload Measurement Techniques: Implications for Their Use in the Assessment of Perceived Mental Workload (Nygren, 1991)

Situation Awareness in Anesthesiology (Gaba \& Howard, 1995) Nestor, 1991)

Note. Inclusion is based on citations in the first 5 years following publication. Papers are listed in order of citation frequency. Total citations include every citation of that paper from the year of publication until May 2001. Note that the paper receiving the greatest number of citations in the 1970s and 1980s may not appear in the table because it may not have been one of the top 10 cited paper within 5 years of publication. 
One would expect that papers published earlier would have garnered more citations than papers published more recently, given that they have been in circulation longer. This is not the case. The mean number of citations for papers is 48.3 in the $1970 \mathrm{~s}, 70.0$ in the $1980 \mathrm{~s}$, and 49.2 in the 1990s. The long half-life of Human Factors suggests that the highly cited papers of the 1990s will continue to accumulate citations and will likely accumulate far more citations than those published in the 1970s. These data suggest an increasingly greater impact for $\mathrm{Hu}$ man Factors. Figure 5 shows this trend with data for all papers published in Human Factors and indicates that the mean citations garnered in the first 5 years after publication has increased more than $150 \%$ in the last 25 years, $F(1,1414)=$ $103.89, p<.0001$. This may reflect the growth of human factors as an academic discipline, the growth of the Human Factors and Ergonomics Society, the growing prestige of Human Factors, or changes in citation conventions.

Figure 5 also shows that the mean number of authors per paper has steadily increased over the last 30 years, moving from an mean of 1.69 in 1970 to 2.96 in $2000, F(1,1680)=209.1, p<$
.0001. Interestingly, impact, as measured by the total citations within 5 years of publication, shows that papers with more authors tend to be cited more frequently, $F(1,1470)=24.36, p<.0001$, with sole-author papers receiving 1.74 citations and five-author papers receiving 3.32 citations during the first 5 years after publication. This surprising result is consistent with similar analysis that showed paper quality, as measured by selection by journal editors for inclusion in the Yearbook of Cancer, was positively associated with the number of coauthors (Lawani, 1986).

The trend of increasing coauthorship is similar to that documented by other bibliometric analyses across many domains (Glanzel, 2002). For example, during the 1980s the mean number of authors per paper increased $48 \%$ in the biomedical area, $24 \%$ in chemistry, and $17 \%$ in mathematics, and the proportion of papers cited within 3 years increased from approximately $47 \%$ for papers with one author to $74 \%$ for papers with more than three authors (Glanzel, 2002). Many factors may be influencing these trends, including progressively more complex investigations that require a multidisciplinary division of labor, the increasing internationalism

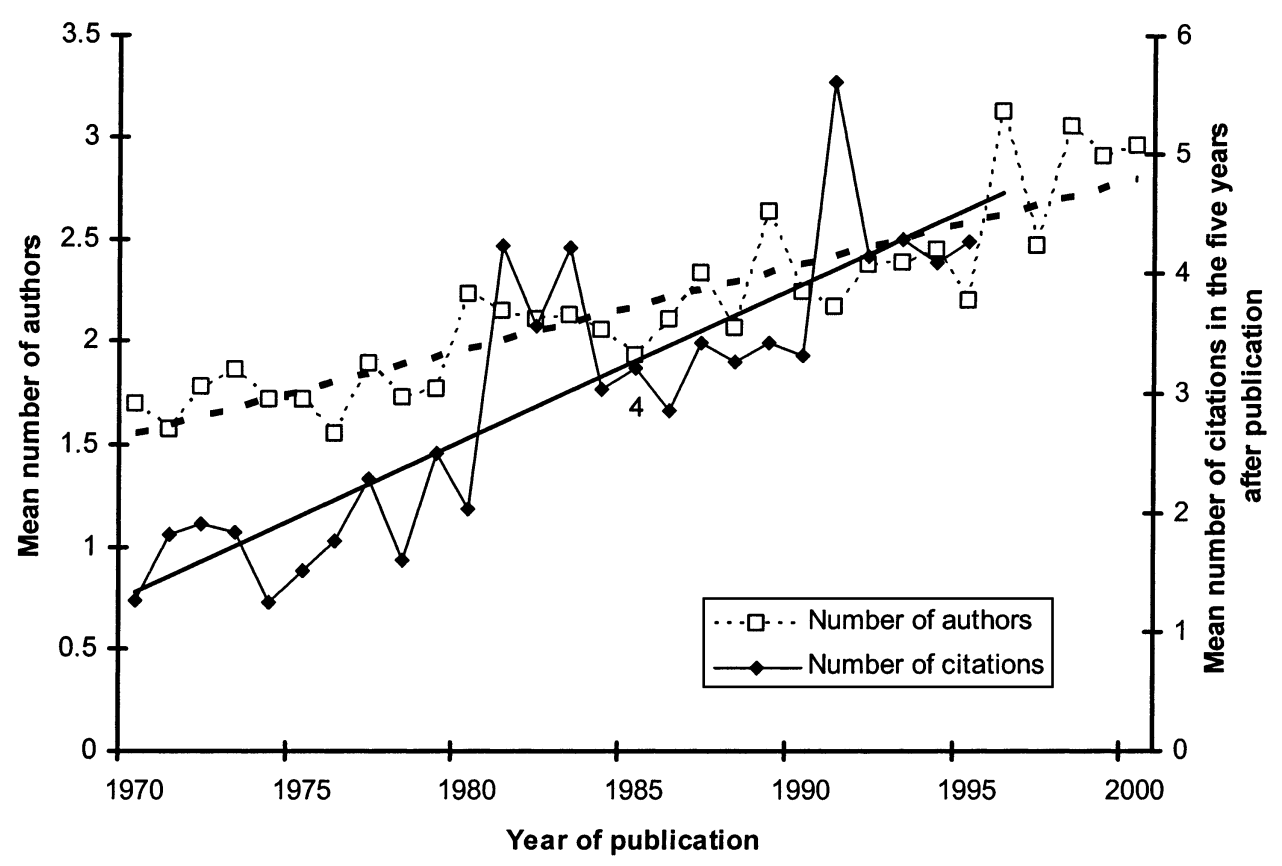

Figure 5. The mean number of citations in the first 5 years after publication and the number of authors contributing to each paper have increased substantially in the last 25 years. 
of scholarship, and the rise of multiperson teams associated with large research programs (Cronin, Shaw, \& La Barre, 2003). These factors all apply to the field of human factors and ergonomics, in which many research problems require a crossdisciplinary perspective. More generally, the trend toward greater collaboration parallels that seen in psychology, and it may reflect a growing similarity among psychology, human factors, and the natural sciences (Cronin et al., 2003).

\section{CONCLUSIONS}

The bibliometric analyses reported here show that Human Factors has substantial influence on scientific progress in the field of human factors and ergonomics, as measured by impact, immediacy, and half-life. A trend toward a greater number of authors per paper in Human Factors parallels that in many fields and may reflect a general trend toward increased emphasis on multidisciplinary analysis of complex systems. In other fields, the number of coauthors is associated with greater impact, and this may be one explanation for the steady increase in the impact of Human Factors.

Although the growing numbers of coauthors may lead to papers with greater impact, bibliometric analyses suggest more direct ways to enhance the impact of Human Factors. Making the full text of all Human Factors papers available on line would likely increase the impact, immediacy, and half-life of the journal. Journal Web sites with more content tend to be more visible, as measured by the number of incoming links. A highly visible Web site would likely increase the use of Human Factors by students and practitioners and might also encourage researchers to choose Human Factors as a publication venue (Vaughan \& Thelwall, 2003). Both impact and immediacy depend on the timely publication of the journal. If an issue is delayed, the opportunity to cite papers in the year of publication greatly diminishes. Furthermore, publication delays may make authors less likely to choose Human Factors as a publication venue. Beyond making Human Factors papers available through timely publication and electronic access, publications such as an annual review issue could help to integrate papers and make them more accessible. Similarly, frequently cited papers identified through bibliometric analysis may merit consideration for inclusion in collections of "suggested readings" that attempt to define the profession (e.g., Baecker \& Buxton, 1987; Venturino, 1990).

Productivity and impact are highly stratified in the field of human factors engineering, as represented by articles in Human Factors, although less so than in many other fields. Relatively few authors account for many papers, and relatively few papers account for the majority of the journal's impact. Highly productive authors tend to be highly cited primarily because they write more papers, not because individual papers are cited more frequently. Two complementary forces help define the degree of stratification in author productivity and citation rates: Diversification tends to reduce stratification, and cumulative advantage tends to accentuate it. Editorial policies, scientific culture, and the education of researchers all influence diversification and cumulative advantage. The degree of author and paper stratification suggests that the field of human factors and ergonomics, as represented by papers in Human Factors over the last 30 years, favors diversification more than other fields do.

This paper presents one set of bibliometric analyses. Many others could provide useful insights into the field, such as analysis of the citation history and relative impact of various topic areas. Co-citation analysis, which examines papers that tend to be cited together and authors that tend to be cited together, is also a particularly promising approach. For example, two earlier papers that are both cited in a third paper are considered to be co-cited (Osareh, 1996). Similarly, two authors that are both cited in one paper are considered to be co-cited. Instances of co-citations identify links between researchers and researcher areas. Co-citations can map the structure of human factors research and show distinct areas of research and communities of practice. It can also identify the core papers of these areas and the evolution of scientific ideas that underlie these areas (Osareh, 1996).

\section{ACKNOWLEDGMENTS}

This research was sponsored, in part, by an E. W. R. Steacie Memorial Fellowship and research grant from the Natural Sciences and Engineering Research Council of Canada and by The 
University of Iowa Bently Engineering Fellowship. The authors would like to thank William Howell, Linda Boyle, and two anonymous reviewers for their helpful comments.

\section{REFERENCES}

Baecker, R. M., \& Buxton, W. A. S. (1987). Readings in humancomputer interaction: A multi-disciplinary approach. Los Altos, CA: Morgan Kaufmann.

Ball, K., \& Owsley, C. (1991). Identifying correlates of accident involvement for the older driver. Human Factors, 33, 583-595.

Bennett, K. B., \& Flach, J. B. (1992). Graphical displays: Implications for divided attention, focused attention, and problem solving. Human Factors, 34, 513-533.

Chapanis, A., Ochsman, R. B., Parrish, R. N., \& Weeks, G. D. (1972). Studies in interactive communication: 1. Effects of four communication modes on behavior of teams during cooperative problem-solving. Human Factors, 14, 487-509.

Clayton, A. B. (1976). Effects of psychotropic drugs upon driving related skills. Human Factors, 18, 241-252.

Cole, J. R., \& Cole, S. (1972). The Ortega hypothesis. Science, 178 , $368-375$.

Craig, A. (1979). Nonparametric measures of sensory efficiency for sustained monitoring tasks. Human Factors, 21, 69-78.

Cronin, B., Shaw, D., \& La Barre, K. (2003). A cast of thousands: Coauthorship and subauthorship collaboration in the 20th century as manifested in the scholarly journal literature of psychology and philosophy. Journal of the American Society for Information Science and Technology, 54, 855-871.

Dennis, W. (1954). Productivity among American psychologists. American Psychologist, 9, 191-194.

Drury, C. G. (1975). Inspection of sheet materials: Model and data. Human Factors, 17, 257-265.

Endsley, M. R. (1995a). Measurement of situation awareness in dynamic systems. Human Factors, 37, 65-84.

Endsley, M. R. (1995b). Toward a theory of situation awareness in dynamic systems. Human Factors, 37, 32-64.

Evans, L. (1985). Human-behavior feedback and traffic safety. Human Factors, 27, 555-576.

Folkard, S., \& Monk, T. H. (1979). Shiftwork and performance. Human Factors, 21, 483-492.

Gaba, D. M., \& Howard, S. K. (1995). Situation awareness in anesthesiology. Human Factors, 37, 20-31.

Garfield, E. (1994). Expected citation rates, half-life, and impact ratios: Comparing apples to apples in evaluation research. Current Contents, 37, 3-5.

Garfield, E. (1999). The journal impact factor: A brief review. Canadian Medical Association Journal, 161, 979-980.

Garfield, E., \& Welljams-Dorof, A. (1992). Of Nobel class: An overview of ISI studies on highly cited authors and Nobel laureates. Theoretical Medicine, 13, 117-135.

Glanzel, W. (2002). Coauthorship patterns and trends in the sciences (1980-1998): A bibliometric study with implications for database indexing and search strategies. Library Trends, 50 $461-473$.

Gould, J. D., \& Grischkowsky, N. (1984). Doing the same work with hard copy and with cathode-ray tube (CRT) computer terminals. Human Factors, 26, 323-337.

Hamilton, D. P. (1991). Research papers: Who's uncited now? Science, 251, 25.

Hitt, J. M. (1998). 10-year (1988-1997) review of the publishing trends in the proceedings of the Human Factors and Ergonomics Society. In Proceedings of the Human Factors and Ergonomics Society 42nd Annual Meeting (pp. 679-682). Santa Monica, CA: Human Factors and Ergonomics Society.

Hull, D. L. (1998). Studying the study of science scientifically. Perspectives on Science, 6, 209-231.

Ikpaahindi, L. (1985). An overview of bibliometrics: Its measurements, laws and their applications. Libri: International Journal of Libraries and Information Services, 35, 163-177.

Kroemer, K. H. E. (1983). An isoinertial technique to assess individual lifting capability. Human Factors, 25, 493-506.
Lawani, S. M. (1986). Some bibliometric correlates of quality in scientific research. Scientometrics, 9, 13-25.

Lawrence, S. (2001). Online or invisible? Nature, 411, 521.

Lee, J. D., Vicente, K. J., Cassano, A., \& Shearer, A. (2003). Can scientific impact be judged prospectively? A bibliometric test of Simonton's model of creative productivity. Scientometrics, $56,223-233$.

Luukkonen, T. (1990). Bibliometrics and evaluation of research performance. Annals of Medicine, 22, 145-150.

Mangun, G. R. R., \& Hillyard, S. A. (1987). The spatial allocation of visual attention as indexed by event-related brain potentials. Human Factors, 29, 195-211.

Marras, W. S., \& Sommerich, C. M. (1991). A three-dimensional motion model of loads on the lumbar spine: 1 . Model structure. Human Factors, 33, 123-137.

Meister, D. (1989). Conceptual aspects of human factors. Baltimore, MD: Johns Hopkins University Press.

Meister, D. (1999). The history of human factors and ergonomics. Mahwah, NJ: Erlbaum.

Merton, R. K. (1968). The Matthew effect in science. Science, 159, 56-63.

Moskowitz, H., \& Sharma, S. (1974). Effects of alcohol on peripheral vision as a function of attention. Human Factors, 16 $174-180$

Narin, F., \& Hamilton, K. S. (1996). Bibliometric performance measures. Scientometrics, 36, 293-310.

Nygren, T.E. (1991). Psychometric properties of subjective workload measurement techniques: Implications for their use in the assessment of perceived mental workload. Human Factors, 33, $17-33$.

Ogden, G. D., Levine, J. M., \& Eisner, E. J. (1979). Measurement of workload by secondary tasks. Human Factors, 21, 529-548.

Osareh, F. (1996). Bibliometrics, citation analysis and co-citation analysis: A review of literature II. Libri: International Journal of Libraries and Information Services, 46, 217-225.

Parasuraman, R., \& Nestor, P. G. (1991). Attention and driving skills in aging and Alzheimer's disease. Human Factors, 33, 539-557.

Peritz, B. C. (1995). On the association between journal circulation and impact factor. Journal of Information Sciences, 21, 63-67.

Price, D. J. (1976). A general theory of bibliometric and other cumulative advantage processes. Journal of the American Society for Information Science, 27, 292-306.

Rouse, W. B. (1979). Problem-solving performance of maintenance trainees in a fault diagnosis task. Human Factors, 21, 195-203.

Rushton, J. P. (1984). Evaluating research eminence in psychology: The construct validity of citation counts. Bulletin of the British Psychological Society, 37, 33-36.

Sanderson, P. M., Flach, J. M., Buttigieg, M. A., \& Casey, E. J. (1989). Object displays do not always support better integrated task performance. Human Factors, 31, 183-198.

Sarter, N. B., \& Woods, D. D. (1995). How in the world did we ever get into that mode? Mode error and awareness in supervisory control. Human Factors, 37, 5-19.

Schneider, W. (1985). Training high-performance skills - Fallacies and guidelines. Human Factors, 27, 285-300.

Schneider, W., \& Detweiler, M. (1988). The role of practice in dualtask performance - Toward workload modeling in a connectionist control architecture. Human Factors, 30, 539-566.

Schoonbaert, D., \& Roelants, G. (1996). Citation analysis for measuring the value of scientific publications: Quality assessment tool or comedy of errors? Tropical Medicine and International Health, 1, 739-752.

Simonton, D. K. (1997). Creative productivity: A predictive and explanatory model of career trajectories and landmarks. Psychological Review, 104, 66-89.

Smith, M. J., Cohen, B. G. F., Stammerjohn, L. W., \& Happ, A. (1981). An investigation of health complaints and job stress in video display operations. Human Factors, 23, 387-400.

Snyder, H., Cronin, B., \& Davenport, E. (1995). What's the use of citation - Citation analysis as a literature topic in selected disciplines of the social sciences. Journal of Information Science, $21,75-85$.

Valero, P., \& Monk, A. (1998). Positioning HCI: Journals, descriptors and parent disciplines. Behaviour and Information Technology, 17, 3-9. 
Vaughan, L., \& Thelwall, M. (2003). Scholarly use of the Web: What are the key inducers of links to journal Web sites? Journal of the American Society for Information Science and Technology, 54, 29-38.

Venturino, M. (1990). Selected readings in human factors. Santa Monica, CA: Human Factors and Ergonomics Society.

Vicente, K. J. (1997). Heeding the legacy of Meister, Brunswik, and Gibson: Toward a broader view of human factors research. Human Factors, 39, 323-328.

White, H. D., \& McCain, K. W. (1989). Bibliometrics. Annual Review of Information Science and Technology, 24, 119-186.

Wickens, C. D., \& Carswell, C. M. (1995). The proximity compatibility principle: Its psychological foundation and relevance to display design. Human Factors, 37, 473-494.

Wickens, C. D., \& Gopher, D. (1977). Control-theory measures of tracking as indexes of attention allocation strategies. Human Factors, 19, 349-365.

Wickens, C. D., Mountford, S. J., \& Schreiner, W. (1981). Multiple resources, task-hemispheric integrity, and individual differences in time-sharing. Human Factors, 23, 211-229.

Wickens, C. D., Sandry, D. L., \& Vidulich, M. (1983). Compatibility and resource competition between modalities of input, central processing, and output: Testing the model of complex task performance. Human Factors, 25, 227-248.

Wierwille, W. W. (1979). Physiological measures of aircrew mental workload. Human Factors, 21, 575-593.

Zavod, M., \& Hitt, J. M. (2000). Summary of the publishing trends of the journal of Human Factors from 1988 to 1997. In Proceedings of the XIVth Triennial Congress of the International
Ergonomics Association and 44th Annual Meeting of the Human Factors and Ergonomics Society (pp. 6.108-6.111).

Santa Monica, CA: Human Factors and Ergonomics Society. Zuckerman, H. (1977). Scientific elite. New York: Free Press.

John D. Lee is an associate professor of mechanical and industrial engineering at the University of Iowa. He received his Ph.D. in mechanical engineering from the University of Illinois at Urbana-Champaign in 1992.

Andrea Cassano-Pinché is working toward her M.A.Sc. in the Department of Mechanical and Industrial Engineering at the University of Toronto, where she received her B.A.Sc. in industrial engineering in 2004.

Kim J. Vicente is a professor of engineering at the University of Toronto. He received his Ph.D. in mechanical engineering in 1991 from the University of Illinois at Urbana-Champaign.

Date received: September 25, 2003

Date accepted: December 22, 2004 